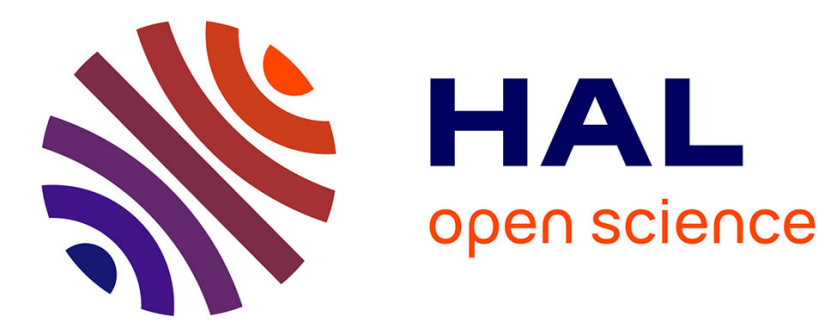

\title{
European plants lagging behind climate change pay a climatic debt in the North, but are favoured in the South \\ François Duchenne, Gabrielle Martin, Emmanuelle Porcher
}

\section{To cite this version:}

François Duchenne, Gabrielle Martin, Emmanuelle Porcher. European plants lagging behind climate change pay a climatic debt in the North, but are favoured in the South. Ecology Letters, 2021, 10.1111/ele.13730 . hal-03178139v1

HAL Id: hal-03178139

https://hal.sorbonne-universite.fr/hal-03178139v1

Submitted on 23 Mar 2021 (v1), last revised 23 Mar 2021 (v2)

HAL is a multi-disciplinary open access archive for the deposit and dissemination of scientific research documents, whether they are published or not. The documents may come from teaching and research institutions in France or abroad, or from public or private research centers.
L'archive ouverte pluridisciplinaire HAL, est destinée au dépôt et à la diffusion de documents scientifiques de niveau recherche, publiés ou non, émanant des établissements d'enseignement et de recherche français ou étrangers, des laboratoires publics ou privés. 


\section{European plants lagging behind climate change pay a climatic debt in the}

\section{North, but are favored in the South}

4 Short title: Climatic debts and bonuses in European plants

5

6 François Duchenne*1,2,3, Gabrielle Martin ${ }^{2,3}$ \& Emmanuelle Porcher ${ }^{2,3}$

7

8 Affiliations:

$9{ }^{1}$ Institute of Ecology and Environmental Sciences of Paris, (Sorbonne Université, CNRS, 10 Université Paris Est Créteil, INRA, IRD), Paris, France, ${ }^{2}$ Centre d'Ecologie et des Sciences de 11 la Conservation, (Muséum national d'Histoire naturelle, CNRS, Sorbonne Université), Paris, 12 France, ${ }^{3}$ Laboratoire Cogitamus, Paris, France

$13 *$ * corresponding author, François Duchenne, francois.duchenne@ mnhn.fr

14 Keywords: range shifts | occupancy trends | climate change | plant distribution | global change

15 drivers

16 Type of article: Letters

17 Number of words in the abstract: 150

18 Number of words in the main text: 4,984

19 Number of references: 45

20 Number of figures: 3 
For many species, climate change leads to range shifts that are detectable, but often

24 insufficient to track historical climatic conditions. These lags of species range shifts behind 25 climatic conditions are often coined "climatic debts", but the demographic costs entailed 26 by the word "debt" have not been demonstrated. Here we used opportunistic distribution 27 data for $\sim 4,000$ European plant species to estimate the temporal shifts in climatic conditions experienced by these species and their occupancy trends, over the last 65 years.

29 The resulting negative relationship observed between these two variables provides the 30 first piece of evidence that European plants are already paying a climatic debt in Alpine, 31 Atlantic and Boreal regions. In contrast, plants appear to benefit from a surprising "climatic bonus" in the Mediterranean. We also find that among multiple pressures faced

33 by plants, climate change is now on par with other known drivers of occupancy trends, 34 including eutrophication and urbanization. 


\section{Introduction}

Climate change is recognized as a major threat for biodiversity (Sala et al. 2000). Species have two main ways to persist under such change: they can track their climatic optimum in space (geographic range shift) or they can respond adaptively to survive and reproduce in a altered environment (Chevin et al. 2010), i.e. modify their climatic optimum. Concerns about the capacity of species to achieve one or the other quickly enough have increased (Parmesan 2006; Chevin et al. 2010; Hoffmann \& Sgrò 2011), with many studies showing that living organisms are currently moving poleward and upward in response to climate warming (Parmesan 2006; Kelly \& Goulden 2008; Devictor et al. 2012; Lenoir et al. 2020). Yet, most studies so far have shown that range shifts are rarely as fast as climate change (Menéndez et al. 2006; Devictor et al. 2012; VanDerWal et al. 2013; Lenoir et al. 2020), i.e. climate variables move faster through space than most species do. This lag of species movements behind climate change is often coined a "climatic debt" (Devictor et al. 2012; Monsinjon et al. 2019; Lenoir et al. 2020). It can be evidenced by a temporal change in the so-called "climatic niche" of a species, as measured by the average of one or several climatic variables throughout its range (VanDerWal et al. 2013), hereafter "species climatic indices" (SCIs).

The consequences of species shifting their ranges slower than the movement of suitable climate conditions, however, remain to be quantified. First, the resulting temporal change in the climatic conditions experienced by a species need not necessarily translate into a "debt": most species can and do also respond to climate change via adaptive plastic or evolutionary trait changes, which could be sufficient to sustain populations despite changing climatic conditions (Hoffmann \& Sgrò 2011), albeit the most recent meta-analysis to date suggests otherwise (Radchuk et al. 2019). Thus, to verify the existence of a true climatic debt, one needs to demonstrate that the spatial lag of species behind changing climate conditions results in decreased individual fitness or population growth; this has not yet been done. Second, most 
species face additional threats beyond climate change, e.g. habitat loss or pollution, which may be the dominant drivers of current species loss (Maxwell et al. 2016). Thus, a climatic debt, should it exist, might be of little consequence for population trends compared to other drivers. However, few studies so far have compared quantitatively the impact of different drivers across a large number of species, and none has included the climatic debt.

Costs associated with the putative climatic debt remain poorly investigated likely because the climatic debt concept has been developed at the community level mostly (Bertrand et al. 2011; Devictor et al. 2012), while cost estimation is easier at species level, e.g. via an assessment of species persistence. By shifting the concept of climatic debt from community to species level, one can correlate delayed spatial responses (i.e. temporal trends in SCIs) with species persistence. Under climate warming, if both species movements and adaptive responses are insufficient, we expect (1) an increase in the temperature SCI of a given species over time (limited spatial response) and (2) a negative relationship between the temporal trend in SCI for temperature and the species persistence (limited adaptive response, Radchuk et al. 2019). The latter observation only is suggestive of costs at individual and population levels, i.e. a climatic debt. Alternatively, uncorrelated SCI trends and species persistence would indicate an absence of climatic debt, which could be explained by adaptive responses buffering limited spatial responses or by species insensitivity to temperature (Rodríguez-Sánchez et al. 2012). This logic applies similarly to other climatic variables beyond temperature, such as precipitation.

Here we examine the temporal shifts in the climatic conditions experienced by a species throughout its range, as measured by SCI trends, and occupancy trends, for more than 4,000 European plant species over the last 65 years, using a large dataset of opportunistic distribution records. These two elements allowed us to verify the existence of a climatic debt, which we estimate via the relationship between occupancy and SCI trends, and to compare its strength to other potential drivers of occupancy trends besides climate change via a trait-based approach. 


\section{Methods}

\section{Data collection; trends in SCIs and species occupancy}

\section{Plant database}

We focused on the most common vascular plant species in geographical Europe, i.e. with at least 500 records in the Global Biodiversity Information Facility (GBIF) database (https://www.gbif.org) between 1950 and 2014 within a rectangle bounded by longitudes [-13ㄹ, $\left.34^{\circ}\right]$ and latitudes $\left[34^{\circ}, 75^{\circ}\right]$. We downloaded all species sightings during the time period from 1951 through 2014, excluding 1950 as this year contains data not precisely dated, but corresponding to the mid-twentieth century. The DOIs associated with the extraction are presented in the Supplementary methods. We considered only records from the European mainland, stopping at $34^{\circ}$ of longitude because there were too few data to the East of this meridian (Fig. S1). Note that the area also includes the western part of Turkey. This yielded a dataset containing $111,549,494$ occurrence records, characterized by a species name, a location and a date. Of these, we analyzed temporal trends in species climatic indices (SCIs) and occupancy only for the species observed in at least 20 years between 1951 and 2014 and with at least one record between 1951 and 1980. We removed crop species and considered invasive species separately (see Supplementary methods), because the drivers of their occupancy trends are likely different from those for non-invasive species. This selection resulted in 4,120 native and naturalized plant species (listed in Table S1), plus 58 invasive species.

\section{Bioclimatic variables}

Climate change is not limited to increases in annual mean temperature; hence we characterized the climatic conditions with three bioclimatic variables related to temperature and three bioclimatic variables related to precipitation, because temperature and precipitation are strong predictors of plant distribution (Franklin et al. 2013). We used previously published European time series (Fréjaville \& Benito Garzón 2018) to extract annual mean temperature, 
maximum temperature of the warmest month, minimum temperature of the coldest month,

111 annual precipitation, precipitation of the wettest month, and precipitation of the driest month.

112 These bioclimatic variables are the same as in Worldclim (bio1, 5, 6, 12, 13, 14) but with annual

113 data. For computational reasons we aggregated $1 \mathrm{kmx} 1 \mathrm{~km}$ raster cells, which decreased spatial

114 resolution from 1 to about $100 \mathrm{~km}^{2}(\sim 10 \mathrm{~km} \times 10 \mathrm{~km})$.

115

116

117

118

119

120

121

122

124

\section{Calculation of annual species climatic indices and their temporal trends}

Species climatic indices (SCIs) are often calculated as the average of a climatic variable, e.g. temperature, across a species range (Devictor et al. 2012). However, the heterogeneity of opportunistic datasets can bias this index (Loiselle et al. 2008; Beck et al. 2014). Because we are interested in inter-annual comparisons, we corrected a temporal bias in the spatial distribution of sampling pressure: the average latitude and longitude of the GBIF records both decrease significantly with time. To reduce such bias we defined annual SCI as the mean climatic variable of all $100 \mathrm{~km}^{2}$ cells occupied by a given species, while weighting the contribution of each cell by the ratio of the number of records of this species on the number of records of all plant species for the given year and grid cell. Such method enables estimations of the SCIs that are more independent from the sampling pressure than a weighting by the number of records of the given species only (Fig. S2).

Following the method above, we calculated one SCI for each bioclimatic variable, species and year. We then assessed the temporal trend in each SCI and species separately, using the following linear model:

$$
S C I_{k}=\mu+\beta \times \operatorname{year}_{k}+\varepsilon_{k}
$$

where $S C I_{k}$ is the species climatic index of year $k, \mu$ is the grand mean (intercept), $\beta$ is the year effect and $\varepsilon_{k}$ is an error term (independent and identically distributed, following $N\left(0, \sigma^{2}\right)$ ). Observations $\left(S C I_{k}\right)$ are weighted by the square root of the number of grid cells included in 
134 their calculation for each year, which gives greater weight to years with more data. We finally

135 estimated the phylogenetic signal in SCI trends (Supplementary Methods).

\section{Occupancy trends}

To model the temporal occupancy trends, we first discretized the dataset spatially and temporally, to define areas occupied or not by a species for a given time period. Such discretization then allowed us to estimate variation in occupancy probability among time periods by taking the sampling pressure into account. As for SCI calculation, we used a grid cell of about $10 \mathrm{~km} \times 10 \mathrm{~km}$ to discretize the dataset spatially, and we aggregated records temporally by years. For each year, a grid cell is considered as visited by at least an observer if it contains at least one plant species record. Non-visited cells are discarded. A visited cell is considered as occupied by a species if it contains at least one record of the given species in the given year, and unoccupied otherwise. We obtained a dataset composed of annual presences and pseudo-absences in each $10 \mathrm{~km} \times 10 \mathrm{~km}$ grid cell.

Before analyzing the data, we discarded all grid cells visited only one year, to improve occupancy estimations by decreasing the confusion between grid cell and year effects (Isaac et al. 2014). To save computing time, for each species we removed non-informative grid cells, i.e. cells with no record of the species over the whole study period. Finally, to estimate a yearly occupancy probability $(p)$, we explained remaining presences and pseudo-absences for each species separately using the following binomial generalized linear model with a logit link:

$$
\log \left(\frac{p_{i k}}{1-p_{i k}}\right)=\mu+\beta_{1} \times \text { year }_{k}+\beta_{2} \times \log \left(S L_{i k}\right)+\varphi_{i}
$$

Where $p_{i k}$ is the occupancy probability of grid cell $i$ for year $k, \mu$ is the intercept of the model, $\beta_{1}$ is the year effect (i.e. the occupancy trend), and $\varphi_{i}$ a random grid cell effect. Finally, $\beta_{2}$ is the effect of the logarithm of the species list length $\left(S L_{i k}\right.$, i.e. the number of species observed in a given grid cell and year), used as a proxy for the sampling pressure (Isaac et al. 2014). 
158 Those models were implemented using the R package glmmTMB (Brooks et al. 2017). We

159 estimated occupancy trends for all 4,120 native and naturalized species, as well as for the 58

160 invasive species. This latter step allowed us to verify that occupancy trend estimates were large

161 and positive for invasive species (Fig. S3), confirming that the data and statistical methods to

162 estimate occupancy trends yield results consistent with known species trends. As for SCI trends,

163 we estimated the phylogenetic signal in occupancy trends (Supplementary Methods).

164

165

166

167

168

169

170

171

172

173

174

175

176

177

178

179

180

181

182

Additional potential drivers of occupancy trends

To compare the strength of the climatic debt with that of other potential drivers of occupancy trends, we tried to include all additional drivers in the analysis of the relationship between occupancy trends and SCI trends (see below). We used the plant and global change literature to identify potential drivers of plant trends, which we took into account via species traits: historical climatic niche (Martin et al. 2019), lifespan (Martin et al. 2019), habitat affinity (Aronson et al. 2014; Buse et al. 2015), nitrophily (Sala et al. 2000; Bobbink et al. 2016), moisture preferences (Moeslund et al. 2013) and pollinator dependency (Biesmeijer et al. 2006). We detail all calculations for these traits in Supplementary Methods.

Species traits, SCI and occupancy trends are available in Table S1.

\section{Evidencing the climatic debt: relationship between SCI trends and occupancy trends}

Analysis at continental scale

As explained above, a climatic debt can be revealed by a negative relationship between species occupancy trends and SCI trends. To assess this relationship between SCI trends and occupancy trends, while controlling for the species traits cited above, we used linear models.

We first checked the correlations among the six SCI trends and six historical climatic niche indices. We noticed high correlations $(r>0.7)$ among historical temperature indices, among historical precipitation indices, among SCI trends related to temperature and among SCI trends related to precipitation (Fig. S4). In order to avoid multicollinearity issues, we retained only the 
183

184

185

186

187

188

189

190

191

192

193

195

196

two most used and integrative bioclimatic variables, both for the historical climatic niche and for SCI trends: annual mean temperature and annual precipitation.

In summary, we considered the following correlates of occupancy trends: SCI trends related to annual mean temperature and annual precipitation, historical climatic index related to annual mean temperature and annual precipitation, nitrophily and moisture Ellenberg indicator values, pollinator dependency, habitat affinity and lifespan. To be able to compare the strength of relations across explanatory variables, we scaled them before using the Phylogenetic Generalized Least Squares regression, except for habitat affinity and lifespan, as we wanted to extract the effect on the intercept for the first and as the second is a qualitative variable. We used the caper R package (Orme et al. 2013) to implement models controlling for phylogenetic signal in the residuals:

$\Delta O_{s j}=\mu+\beta_{1} \times \Delta S C I_{{\text {bio } 1_{s}}_{1}}+\beta_{2} \times \Delta S C I_{{\text {bio } 2_{s}}_{s}}+\beta_{3} \times B C I_{\text {bio } 1_{s}}+\beta_{4} \times B C I_{\text {bio } 12_{s}}+\beta_{5} \times$

$M E_{s}+\beta_{6} \times N E_{s}+\beta_{7} \times$ Poll $_{s}+\theta_{j}+\sum_{i=1}^{h} \beta_{\text {habitat }_{i}} \times$ Habitat $_{i}+\varepsilon_{s j}$

Where $\Delta O_{s j}$ is the occupancy trend of species $s$ with lifespan class $j, \mu$ is the grand mean (intercept), $\beta_{1}$ and $\beta_{2}$ are the slopes of SCI trends, $\beta_{3}$ and $\beta_{4}$ are the effects of historical climatic niche indices, $B C I_{b i o 1}$ and $B C I_{b i o 12}$, related to annual mean temperature and annual precipitation respectively. $\beta_{5}$ and $\beta_{6}$ are the effects of Ellenberg indicator values for moisture and nitrogen respectively. $\beta_{7}$ is the effect of pollinator dependency, $\theta_{j}$ is the qualitative lifespan effect and $\beta_{\text {habitat }_{i}}$ is the effect of affinity to habitat $i$, with six habitat classes ( $h=6$, Table S2), woodland being the reference habitat. Finally, $\varepsilon_{s j}$ is an error term, after correction by Pagel's $\lambda$ value at the likelihood maximum.

This model included all species matching the phylogeny and with full trait data $(n=2,013)$. To add the 67 species that were not in the phylogeny but for which all traits were available, we also performed a linear mixed-effect model similar to the phylogenetic regression but including 
random taxonomic effects of class $\left(\varphi_{c}\right)$ and of family nested in class $\left(\varphi_{f}\right)$ instead of a

208 phylogeny:

$\Delta O_{s j c f}=\mu+\beta_{1} \times \Delta S C I_{\text {bio }_{s}}+\beta_{2} \times \Delta S C I_{{\text {bio } 12_{s}}_{s}}+\beta_{3} \times B C I_{b i o 1_{s}}+\beta_{4} \times B C I_{b i o 12_{s}}+\beta_{5} \times$

$M E_{s}+\beta_{6} \times N E_{s}+\beta_{7} \times$ Poll $_{s}+\theta_{j}+\sum_{i=1}^{h} \beta_{\text {habitat }_{i}} \times$ Habitat $_{i}+\varphi_{c}+\varphi_{f}+\varepsilon_{s j c f}$

211 This linear mixed-effect model was weighted by the inverse of the standard errors associated

212 with the occupancy trends.

Analysis by biogeographic region and time period

To examine the spatial variation in climatic debt, we also conducted the same analysis

215 within biogeographic regions. We focused on the five biogeographic regions with at least 1,000 species: Alpine, Atlantic, Boreal, Continental and Mediterranean regions. For each region, as for the main analysis, we retained only species with at least 20 years of data.

We re-calculated SCI and occupancy trends within each region independently, using the same method as above, but including only plant records from the focal biogeographic region. With these new estimates, we assessed regional climatic debts as the relationship between SCI and occupancy trends, using the same models as in the European analysis (equations (3) and (4)) but removing the random effect of taxonomic class $\varphi_{c}$, to avoid singularities. While SCI and occupancy trends were calculated within biogeographic regions, we considered other species traits as constant throughout Europe.

Finally, to confirm that the costs of the shifts in experienced climatic conditions occur only after the acceleration of climate change (1980-2000, Fig. S5) we performed the same set of analyses on the earliest data, as detailed in Supplementary Methods. Results are shown in Fig. S6. 
Combining the effects of precipitation and temperature SCI trends to estimate an overall

To combine the effects of annual precipitation and temperature SCI trends on occupancy trends for each biogeographic region, we multiplied each unscaled effect of SCI trends by the observed change in the corresponding climatic indices. This yielded a measure of the effective cost/bonus due to a given SCI trend, i.e. to the lag of species behind climate change. For each region, we then summed the values of effective cost/bonus for temperature and precipitation to measure the overall climatic debt/bonus over the study period. We also calculated the relative contribution of precipitation and temperature SCI trends to the overall debt/bonus by dividing each by the sum of the absolute values of both.

\section{Results}

\section{Temporal trends in Species Climatic Indices}

During the study period (1951-2014), all SCIs change significantly, in direct relation with 242 climate change. All bioclimatic variables related to temperature and precipitation increase on average over the study area, but with substantial spatial heterogeneity for precipitation (Fig. S5). Consistently with the trends in bioclimatic variables related to temperature, we show that the temperature SCIs increase over time for a large majority of species (Fig. 1). Precipitation

246 SCIs also increase over time on average (Fig. 1, Table S3), but the distribution of precipitation 247 SCI trends is closer to zero, with more numerous negative trends than for temperature SCIs. 248 Temperature and precipitation SCI trends are not significantly correlated (Fig. S4), probably 249 due to the fact that annual precipitation and temperature trends exhibit contrasting spatial 250 distributions (Fig. S5c-d). We also find a significant phylogenetic signal in all SCI trends (Fig. 251 S7). 


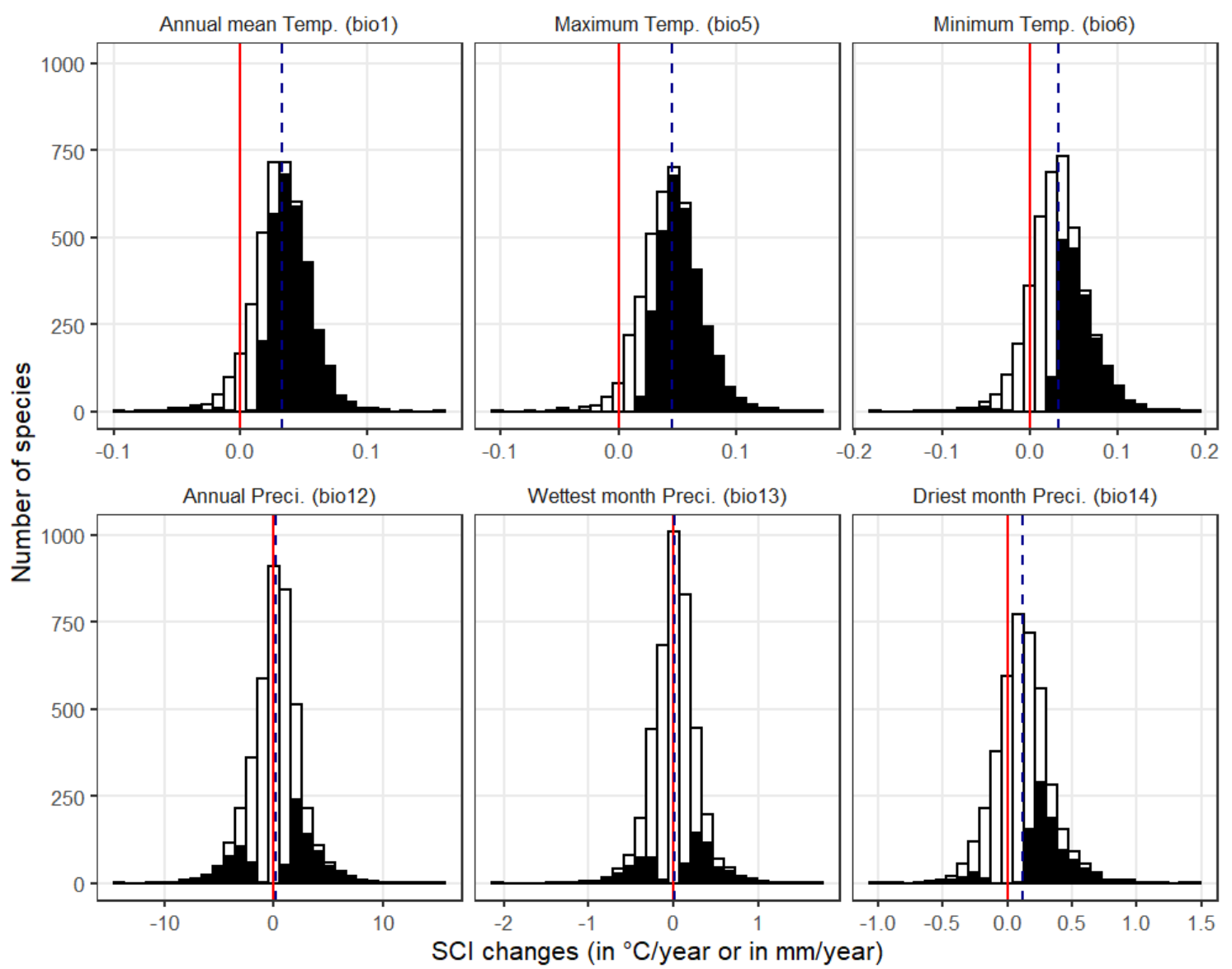

Figure 1: Linear trends in species climatic indices (SCIs) for all species $(n=4,120)$. The first row shows the trends in temperature SCIs and the second row the trends in precipitation SCIs over time. The WorldClim abbreviation for bioclimatic variables is indicated in parentheses atop each panel. The vertical red line indicates zero (no change across years) while the vertical dashed blue lines show the average values across the 4,120 species. Filled bars represent the count of species with significant trends ( $p$-value $<0.05$ ) whereas open bars represent the count of species with non-significant trend ( $p$-value $>0.05$ ).

\section{Occupancy trends and their drivers}

The average trend in occupancy over all native and naturalized species is slightly positive: $0.0048 \pm 3.2910^{-4}$ year $^{-1}$ (mean $\pm \mathrm{SE}$ ), but the number of species with significant increase in the occupancy estimates $(1,721$ species, $42 \%)$ is comparable to the number of species with significant decline in occupancy (1,519 species, 37\%). The average positive trend over all species (Fig. 2a) is mainly explained by the skewed distribution of trends towards positive values, with a couple of species exhibiting strong increases even after exclusion of invasive species (Fig. S3). Furthermore, we find that plant occupancy trends exhibit a strong 

$\left.=0.45, \mathrm{CI}_{95 \%}=[0.32,0.57] ; n=2,013\right)$ considering species traits.
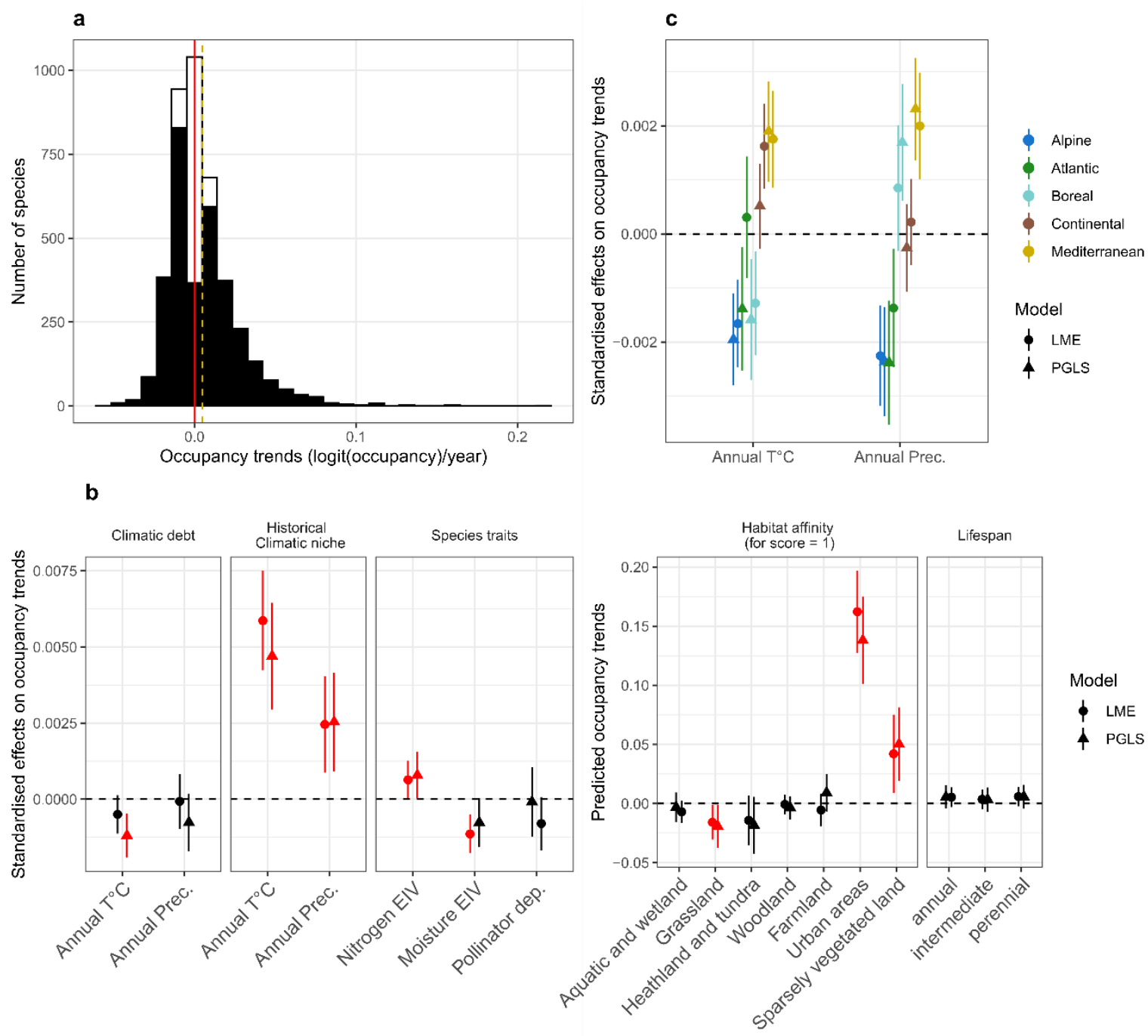

Figure 2: Occupancy trends of native and naturalized European plant species and their correlates. (a) Histogram of occupancy trends, on a logit scale $y^{-1}$. The red vertical line indicates zero while the vertical dashed yellow line shows the average value $(n=4,120)$. Filled bars represent the count of species with significant trends ( $p$-value $<0.05)$ whereas open bars represent the count of species with non-significant trends (p-value>0.05). (b) The three left panels represent the estimates ( \pm CI $\left.1_{95 \%}\right)$ from phylogenetic regressions $(P G L S, n=2,013)$ and linear mixed-effect model (LME, $n=2,080$, see Methods) explaining occupancy trends with temporal trends in species climatic indices (SCIs) and other species traits. The two right panels show predicted averaged occupancy trends $\left( \pm C I_{95 \%}\right)$ for annual species with complete affinity for each habitat (habitat affinity score $=1$ and lifespan = annual), and for lifespan categories, predicted at the average of all other variables. Red symbols represent significant effects while black symbols represent non-significant correlations. (c) Estimates ( \pm CI $\left.1_{95 \%}\right)$ from PGLS and LME of the effect of standardized temperature and precipitation SCI trends on occupancy trends, for each biogeographic region.

The analysis of the correlates of species occupancy trends reveals that plant species pay a 
relationship between SCI trends and occupancy trends is not significant (Fig. 2b), analysis by 289 biogeographic regions reveals significant correlations, with a strong heterogeneity among regions and across bioclimatic variables. Regarding temperature, in the two coldest biogeographic regions (i.e. Boreal and Alpine regions), a temporal increase in temperature throughout a species range, a consequence of an insufficient range shift to keep pace with historical climatic conditions, is associated with more negative occupancy trends over time (Fig. 2c). Surprisingly, in the warmest Mediterranean region, the opposite pattern is observed: species that have experienced a temperature increase throughout their range tend to increase (Fig. 2c), suggesting that climate change elicits a bonus instead of a debt in this area. Regarding precipitation, plant species occupancy trends are negatively related with precipitation SCI trends in the Alpine and Atlantic regions with the highest rainfall, while this relationship tends to be positive in the drier Boreal, Mediterranean and Continental regions (Fig. 2c). expected effects of the historical climatic niche (Fig. 2b), that however vary in space. At the continental scale, species from rainy and warm historical niches exhibit higher occupancy trends. However, within biogeographic regions, the advantage of warm historical niches was observed only in cooler parts of Europe (Boreal, Atlantic and Alpine regions, Fig. S8). Similarly, the benefit of rainy niches is seen in Boreal and Continental regions only (Fig. S8), where rainfall has increased the most (Fig. S5), while species with dry niches seem to be favored in the Alpine region with decreasing precipitation (Fig. S8). variables, are a climatic debt in Alpine, Atlantic and Boreal regions (Fig. 3a), but a climatic 310 bonus in the Mediterranean (Fig. 3a), driven mostly by temperature changes but with a 311 significant contribution of precipitation locally (Fig. 3b,c). In the Continental region the 312 observed lags in range shifts did not have any overall significant effect on plant persistence 
(Fig. 3a), although when combining all the non-significant effects, lags in range shifts tended

to benefit plants there, similarly to the Mediterranean region (Fig. S9). The examination of the

relative contributions of temperature and precipitation SCI trends to the climatic debt/bonus

316 shows that temperature is generally the major driver (Fig 3c), except in the Atlantic region,

317 where precipitation shifts are the only significant driver of estimated climatic costs.

318 Importantly, SCI and occupancy trends are not significantly related during 1951-1990 (Fig. S6),

319 when climate was relatively stable.

320 Finally, plant occupancy trends are also expectedly related to other drivers beyond climate

321 change. At a continental scale, nitrophily and urban affinity are significant correlates of plant

322 occupancy trends (Fig. 2b). We also find a negative but non-significant effect of pollinator

323 dependency on occupancy trends (Fig. 2b). A majority of the remaining variables, such as most

324 habitat affinities except urban affinity and moisture preferences, have contrasting effects on

occupancy trends across biogeographic regions (Fig. S8).
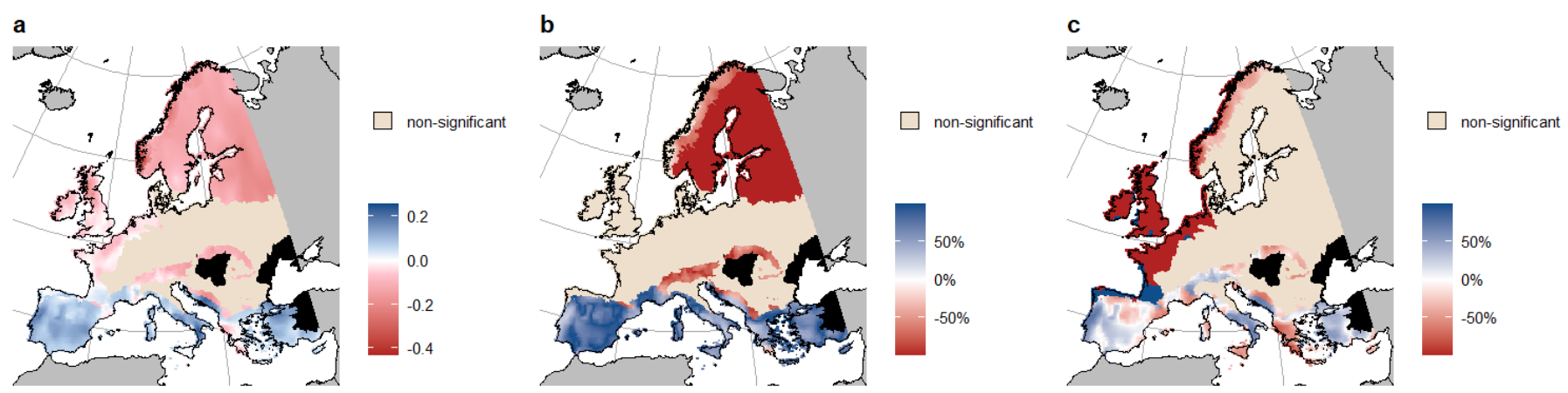

Figure 3: Climatic debt/bonus in Europe and its climatic drivers. (a) Climatic debt/bonus averaged over all species over the last 65 years. The gradient from white to red indicates a climatic debt (cost of climate change in terms of species occupancy), while the gradient from white to blue indicates a climatic bonus (benefits of climate change in terms of species occupancy); white represents no cost of range shift lags on average for plants. Relative contribution of trends in species climatic indices (SCIs) related to (b) temperature and (c) precipitation to the climatic debt/bonus, in percentage. Black regions are biogeographic regions with too few data. The maps were generated using only predictions for effects of SCI trends that are significant in both the phylogenetic regression and the linear mixed-effect model averaged over these two models. 
Our study of the consequences of climate change for plant species first confirms a spatial

338 lag in species responses to climate change, evidenced by an increase in both temperature and precipitation SCIs (Fig.1) suggesting that species are not moving fast enough to track their historical climatic conditions (i.e. to keep constant SCIs). Those SCI trends are phylogenetically structured, which could be explained by the already known climatic niche conservatism in 342 plants (Prinzing Andreas et al. 2001; Preston \& Sandve 2013; Hawkins et al. 2014; Liu et al. 343 2015) but also by the phylogenetic structure in the ability of plant species to track their optimum spatially via colonization (Baeten et al. 2015). Furthermore, we also find that temperature and precipitation exhibit contrasting temporal trends in Europe, inducing uncorrelated SCI changes and possibly leading to a spatial trade-off for European plants between tracking precipitation and temperature historical conditions, as has been shown along the elevation gradient 348 (Crimmins et al. 2011).

Analyses within biogeographic regions reveal that the lag in species response to temperature change translated into a climatic debt in the North but a surprising climatic "bonus" in the South, resulting in no overall significant signal for a climatic debt at the European scale. However, differences between northern and southern Europe are consistent with a climatic debt at a continental scale: species that track climate change spatially, i.e. with SCI trends close to zero, have positive occupancy trends on their leading edge (northern margins) but negative trends on their trailing edge (southern margins). In addition, among-region differences also match regional patterns of correlations between occupancy trends and historical climatic niche, suggesting that climate could have distinctive effects among regions.

In Boreal and Alpine regions, the effect of temperature SCI trends comes in addition to an effect of the historical climatic niche, with larger occupancy trends for species from historically warmer area. This pattern is consistent with previous results on French plants (Martin et al. 
2019), and its significance only in the cooler parts of Europe (Fig. S8) confirms the well-known

362 stronger effect of climate warming at higher latitudes (Parmesan 2007). Occupancy trends correlate significantly both with temperature SCI trends and temperature of the historical niche

364 in cooler parts of Europe, suggesting that climate is an important driver of species persistence 365 in these areas. In contrast, the surprising climatic bonus in the Mediterranean region is 366 consistent with the absence of correlation between the historical climatic niche and occupancy 367 trends there, suggesting that climate is currently not a strong driver of plant occupancy trends 368 in this area, as previously shown for colonization patterns (Normand et al. 2011). This unexpected climatic bonus, which is generally overlooked, could be caused by changes in competitive interactions, an important driver of species responses to climate change (Alexander et al. 2015), although we cannot exclude a role of other types of interspecific interactions, such

372 as facilitation or herbivory (Descombes et al. 2020). Plants with limited or no northward shift 373 (i.e. plants with an increasing temperature SCI) may benefit from competitive release associated 374 with the range shift of more mobile species, without being in competition with novel 375 competitors from southern regions, because of the numerous geographic barriers limiting plant 376 colonization in the Mediterranean region (Normand et al. 2011). These apparent benefits may 377 however disappear when focusing on the whole Mediterranean region: here we ignored the 378 southern margin of many Mediterranean plants, located in Northern Africa, a region with few 379 plant records. Moreover, this climatic bonus is likely to be reversed by sustained climate 380 change on the longer term, when climatic conditions exceed the climatic tolerance of species.

381 In addition to these effects of temperature, the climatic debt can also be driven by changes 382 in precipitation, albeit to a lesser extent. When we combine the effects of temperature and 383 precipitation SCI trends, we show that the inability of plant species to track their historical 384 climatic conditions has been costly in the Alpine, Atlantic and Boreal regions, but beneficial in 385 the Mediterranean region. These patterns substantiate further the notion of climatic debt in the 
former areas, and confirm the climatic bonus in the Mediterranean, although lags behind climate

387 are most often interpreted as a climatic debt there (Bertrand et al. 2016). The effects of lagging

388 behind changing precipitation are variable however. In relatively dry biogeographic regions, a

389 decrease in the annual precipitation SCI of plant species over the past decades is associated

390 with negative, or less positive, occupancy trends, which suggests that climate change causes

391 water-deficit stress with detrimental consequences for plant population dynamics, a well-known

392 phenomenon (Breshears et al. 2005; Allen et al. 2010; Zhao \& Running 2010). This applies to

393 the Mediterranean region, in which precipitation shifts can be as important a driver as

394 temperature changes, although it is widely overlooked in climatic debt assessments.

In contrast, in relatively wet areas, plant occupancy trends seem to be hindered by an increase in annual precipitation SCI, which suggests water-excess stress, via e.g. waterlogging. Such consequence of climate change, via an increase in precipitation, is less documented but has been shown to drive downhill shifts in plant species elevation against temperature changes in mountain areas (Crimmins et al. 2011). Their general contribution to the climatic debt relative to temperature is however moderate, except in the Atlantic region.

Beyond the effects of climate change, our results also strongly suggest that nitrogen deposition and urbanization are important disturbances for plants (Aronson et al. 2014; Bobbink et al. 2016). However, while nitrogen deposition is sometimes cited as the first driver of changes in plant species composition (Bobbink et al. 2016), our results challenge this statement: by assessing response traits simultaneously, we find stronger links of occupancy trends with historical climatic niche or urban affinity than with nitrophily. Hence, our results are consistent with the recent acceleration of climate change in Europe and suggest that climate warming has 408 caught up with urbanization and nitrogen deposition to become an important driver of plant 409 persistence. We thus provide further evidence that biodiversity is often affected by multiple 410 global change drivers rather than by single threats (Brooks et al. 2017). Consistent with 
411 previous results and with the pollinator decline (Biesmeijer et al. 2006), we find a negative 412 effect of pollinator dependency on occupancy trends, but the latter is non-significant. This lack 413 of signal for an effect of pollinator loss on plant occupancy trends may be attributable to 414 contrasting plant trends depending on the group of pollinators (Biesmeijer et al. 2006).

Here we show that plants are under multiple pressures from global change, and that plant occupancy trends exhibit a strong phylogenetic signal, which entails a risk of important evolutionary history losses associated with the forecasted extinctions. In particular, in some regions plant persistence is already affected by climate change and the resulting climatic debt/bonus, while these climate-related costs/benefits are often considered long-term. The climatic debt/bonus evident here is an integrative measure of all ecological and evolutionary costs/benefits associated with climate change, which we are not able to partition. For example, the costs we observe in Northern Europe could be due to insufficient adaptive response to buffer a spatial lag, to the arrival of novel competitors (Alexander et al. 2015), and/or to the demographic cost of an ongoing adaptive response (Lynch \& Lande 1993) buffering the spatial lag. As plant adaptation to climate change opens the door to a possible evolutionary rescue for species that track their climatic optimum poorly in space (Gonzalez et al. 2013), assessing the contribution of ecological and evolutionary mechanisms of the climatic debt or bonus is a remaining key challenge to predict future effects of climate change on plants.

Although this study tackled two dimensions of the species climatic niches simultaneously, our estimation of the climatic debt faces some limitations. First, we examined average climatic 431 conditions only, thereby probably underestimating the cost of climate change, which also 432 includes changes in variability, such as in the frequency of extreme events. Moreover, other 433 environmental conditions beyond climate have changed during the last decades, such that their 434 effects are difficult to unravel. Our climatic debt/bonus measure is thus integrative, likely 435 including costs related to interactions between climate change and other drivers. For example 
436 landscape alteration can hinder species tracking of their historical climatic conditions (Bertrand

437 et al. 2016; Gaüzère et al. 2017). We used a correlative approach on the basis of species traits,

438 while taking phylogeny into account: the remaining phylogenetic signal in plant occupancy

439 trends points to a likely omission either of some drivers or of synergistic effects among drivers.

440 These could be investigated through local studies.

441 Finally, we present the first overview of plant occupancy trends at continental scale. This

442 was made possible by the use of opportunistic data, which are often the only data source to

443 obtain long time-series at large spatial extent (Biesmeijer et al. 2006; Bartomeus et al. 2019),

444 together with statistical methods aiming to correct the potential biases associated with those

445 data (Isaac et al. 2014). The fact that we find strong positive trends for invasive species suggests

446 that trends estimated from GBIF data provide an accurate picture of actual changes in species

447 occupancy. However, finding independent datasets and methods that allow turning the clock

448 back and studying past effects of global change on biodiversity is a major challenge to confirm

449 our results and anticipate future threats for biodiversity. 


\section{Acknowledgments}

451 We thank the GBIF institution and GBIF data providers for building the database, making it 452 publicly available and populating it. Statistical computation was partly performed at the 453 HPCaVe center of Sorbonne Université. This project was funded by the Ministère de la 454 Transition Écologique et Solidaire as part of the project "What is the sensitivity of pollinators 455 to global warming in France" (convention $n^{\circ}$ SJ 3-17) led by Christophe Daugeron and Colin 456 Fontaine, by the Institut de la Transition Écologique, Sorbonne Université, as part of the project 457 Yapludsaison and by a grant from the Program Hubert Curien Alliance 2020.

\section{Author Contributions}

459 FD designed the study, extracted the data and performed all the statistical analyses. GM and 460 FD extracted and compiled species traits. FD and EP wrote the paper with contributions from 461 GM.

\section{Competing interests}

The authors declare no competing interests.

\section{Data availability statement}

$\mathrm{R}$ scrips used to perform the analysis are available here: https://github.com/f-

duchenne/European-plants-lagging-behind-climate-change-. All data supporting the analysis, excepting row data from the GBIF, can be downloaded here:

\section{References:}

Alexander, J.M., Diez, J.M. \& Levine, J.M. (2015). Novel competitors shape species' responses to climate change. Nature, 525, 515-518. al. (2010). A global overview of drought and heat-induced tree mortality reveals 
emerging climate change risks for forests. For. Ecol. Manag., Adaptation of Forests and Forest Management to Changing Climate, 259, 660-684.

Aronson, M.F.J., La Sorte, F.A., Nilon, C.H., Katti, M., Goddard, M.A., Lepczyk, C.A., et al. (2014). A global analysis of the impacts of urbanization on bird and plant diversity reveals key anthropogenic drivers. Proc. R. Soc. B Biol. Sci., 281, 20133330.

Baeten, L., Davies, T.J., Verheyen, K., Calster, H.V. \& Vellend, M. (2015). Disentangling dispersal from phylogeny in the colonization capacity of forest understorey plants. $J$. Ecol., 103, 175-183.

Bartomeus, I., Stavert, J.R., Ward, D. \& Aguado, O. (2019). Historical collections as a tool for assessing the global pollination crisis. Philos. Trans. R. Soc. B Biol. Sci., 374, 20170389.

Beck, J., Böller, M., Erhardt, A. \& Schwanghart, W. (2014). Spatial bias in the GBIF database and its effect on modeling species' geographic distributions. Ecol. Inform., 19, 10-15.

Bertrand, R., Lenoir, J., Piedallu, C., Riofrío-Dillon, G., de Ruffray, P., Vidal, C., et al. (2011). Changes in plant community composition lag behind climate warming in lowland forests. Nature, 479, 517-520.

Bertrand, R., Riofrío-Dillon, G., Lenoir, J., Drapier, J., de Ruffray, P., Gégout, J.-C., et al. (2016). Ecological constraints increase the climatic debt in forests. Nat. Commun., 7, 12643.

Biesmeijer, J.C., Roberts, S.P.M., Reemer, M., Ohlemüller, R., Edwards, M., Peeters, T., et al. (2006). Parallel Declines in Pollinators and Insect-Pollinated Plants in Britain and the Netherlands. Science, 313, 351-354.

Bobbink, R., Hicks, K., Galloway, J., Spranger, T., Alkemade, R., Ashmore, M., et al. (2016). Global assessment of nitrogen deposition effects on terrestrial plant diversity: a synthesis. Ecol. Appl., 30-59.

Breshears, D.D., Cobb, N.S., Rich, P.M., Price, K.P., Allen, C.D., Balice, R.G., et al. (2005). Regional vegetation die-off in response to global-change-type drought. Proc. Natl. Acad. Sci., 102, 15144-15148.

Brooks, M.E., Kristensen, K., Benthem, K.J. van, Magnusson, A., Berg, C.W., Nielsen, A., et al. (2017). glmmTMB Balances Speed and Flexibility Among Packages for Zeroinflated Generalized Linear Mixed Modeling. $R$ J., 9, 378-400.

Buse, J., Boch, S., Hilgers, J. \& Griebeler, E.M. (2015). Conservation of threatened habitat types under future climate change - Lessons from plant-distribution models and current extinction trends in southern Germany. J. Nat. Conserv., 27, 18-25.

Chevin, L.-M., Lande, R. \& Mace, G.M. (2010). Adaptation, Plasticity, and Extinction in a Changing Environment: Towards a Predictive Theory. PLOS Biol., 8, e1000357.

Crimmins, S.M., Dobrowski, S.Z., Greenberg, J.A., Abatzoglou, J.T. \& Mynsberge, A.R. (2011). Changes in Climatic Water Balance Drive Downhill Shifts in Plant Species' Optimum Elevations. Science, 331, 324-327.

Descombes, P., Pitteloud, C., Glauser, G., Defossez, E., Kergunteuil, A., Allard, P.-M., et al. (2020). Novel trophic interactions under climate change promote alpine plant coexistence. Science, 370, 1469-1473.

Devictor, V., van Swaay, C., Brereton, T., Brotons, L., Chamberlain, D., Heliölä, J., et al. (2012). Differences in the climatic debts of birds and butterflies at a continental scale. Nat. Clim. Change, 2, 121-124.

Franklin, J., Davis, F.W., Ikegami, M., Syphard, A.D., Flint, L.E., Flint, A.L., et al. (2013). Modeling plant species distributions under future climates: how fine scale do climate projections need to be? Glob. Change Biol., 19, 473-483.

Fréjaville, T. \& Benito Garzón, M. (2018). The EuMedClim Database: Yearly Climate Data (1901-2014) of $1 \mathrm{~km}$ Resolution Grids for Europe and the Mediterranean Basin. Front. Ecol. Evol., 6. 
Gaüzère, P., Princé, K. \& Devictor, V. (2017). Where do they go? The effects of topography and habitat diversity on reducing climatic debt in birds. Glob. Change Biol., 23, 22182229.

Gonzalez, A., Ronce, O., Ferriere, R. \& Hochberg, M.E. (2013). Evolutionary rescue: an emerging focus at the intersection between ecology and evolution. Philos. Trans. R. Soc. B Biol. Sci., 368.

Hawkins, B.A., Rueda, M., Rangel, T.F., Field, R. \& Diniz-Filho, J.A.F. (2014). Community phylogenetics at the biogeographical scale: cold tolerance, niche conservatism and the structure of North American forests. J. Biogeogr., 41, 23-38.

Hoffmann, A.A. \& Sgrò, C.M. (2011). Climate change and evolutionary adaptation. Nature, 470, 479-485.

Isaac, N.J.B., Strien, A.J. van, August, T.A., Zeeuw, M.P. de \& Roy, D.B. (2014). Statistics for citizen science: extracting signals of change from noisy ecological data. Methods Ecol. Evol., 5, 1052-1060.

Kelly, A.E. \& Goulden, M.L. (2008). Rapid shifts in plant distribution with recent climate change. Proc. Natl. Acad. Sci., 105, 11823-11826.

Lenoir, J., Bertrand, R., Comte, L., Bourgeaud, L., Hattab, T., Murienne, J., et al. (2020). Species better track climate warming in the oceans than on land. Nat. Ecol. Evol., 1-16.

Liu, H., Xu, Q., He, P., Santiago, L.S., Yang, K. \& Ye, Q. (2015). Strong phylogenetic signals and phylogenetic niche conservatism in ecophysiological traits across divergent lineages of Magnoliaceae. Sci. Rep., 5, 1-12.

Loiselle, B.A., Jørgensen, P.M., Consiglio, T., Jiménez, I., Blake, J.G., Lohmann, L.G., et al. (2008). Predicting species distributions from herbarium collections: does climate bias in collection sampling influence model outcomes? J. Biogeogr., 35, 105-116.

Lynch, M. \& Lande, R. (1993). Evolution and extinction in response to environmental change. In: Biotic Interactions and Global Change. Sinauer Assocs, Inc. Sunderland, San Juan Island, WA (United States), pp. 234-250.

Martin, G., Devictor, V., Motard, E., Machon, N. \& Porcher, E. (2019). Short-term climateinduced change in French plant communities. Biol. Lett., 15, 20190280.

Maxwell, S.L., Fuller, R.A., Brooks, T.M. \& Watson, J.E.M. (2016). Biodiversity: The ravages of guns, nets and bulldozers. Nat. News, 536, 143.

Menéndez, R., Megías, A.G., Hill, J.K., Braschler, B., Willis, S.G., Collingham, Y., et al. (2006). Species richness changes lag behind climate change. Proc. R. Soc. B Biol. Sci., 273, 1465-1470.

Moeslund, J.E., Arge, L., Bøcher, P.K., Dalgaard, T., Ejrnæs, R., Odgaard, M.V., et al. (2013). Topographically controlled soil moisture drives plant diversity patterns within grasslands. Biodivers. Conserv., 22, 2151-2166.

Monsinjon, J.R., Wyneken, J., Rusenko, K., López-Mendilaharsu, M., Lara, P., Santos, A., et al. (2019). The climatic debt of loggerhead sea turtle populations in a warming world. Ecol. Indic., 107, 105657.

Normand, S., Ricklefs, R.E., Skov, F., Bladt, J., Tackenberg, O. \& Svenning, J.-C. (2011). Postglacial migration supplements climate in determining plant species ranges in Europe. Proc. R. Soc. B Biol. Sci., 278, 3644-3653.

Orme, D., Freckleton, R., Thomas, G., Petzoldt, T., Fritz, S., Isaac, N., et al. (2013). caper: Comparative Analyses of Phylogenetics and Evolution in $R$.

Parmesan, C. (2006). Ecological and Evolutionary Responses to Recent Climate Change. Annu. Rev. Ecol. Evol. Syst., 37, 637-669.

Parmesan, C. (2007). Influences of species, latitudes and methodologies on estimates of phenological response to global warming. Glob. Change Biol., 13, 1860-1872. 
Preston, J.C. \& Sandve, S.R. (2013). Adaptation to seasonality and the winter freeze. Front. Plant Sci., 4.

Prinzing Andreas, Durka Walter, Klotz Stefan, \& Brandl Roalnd. (2001). The niche of higher plants: evidence for phylogenetic conservatism. Proc. R. Soc. Lond. B Biol. Sci., 268, 2383-2389.

Radchuk, V., Reed, T., Teplitsky, C., Pol, M. van de, Charmantier, A., Hassall, C., et al. (2019). Adaptive responses of animals to climate change are most likely insufficient. Nat. Commun., 10, 1-14.

Rodríguez-Sánchez, F., Frenne, P.D. \& Hampe, A. (2012). Uncertainty in thermal tolerances and climatic debt. Nat. Clim. Change, 2, 636-637.

Sala, O.E., Chapin, F.S., Iii, Armesto, J.J., Berlow, E., Bloomfield, J., et al. (2000). Global Biodiversity Scenarios for the Year 2100. Science, 287, 1770-1774.

VanDerWal, J., Murphy, H.T., Kutt, A.S., Perkins, G.C., Bateman, B.L., Perry, J.J., et al. (2013). Focus on poleward shifts in species' distribution underestimates the fingerprint of climate change. Nat. Clim. Change, 3, 239-243.

Zhao, M. \& Running, S.W. (2010). Drought-Induced Reduction in Global Terrestrial Net Primary Production from 2000 Through 2009. Science, 329, 940-943. 